\title{
El cuerpo espasmático en “1973 La Tormenta” de Ricardo Fuentealba
}

\author{
Jorge Sánchez Sánchez \\ Universidad de Santiago de Chile \\ Universidad San Sebastián \\ jorge.sanchez.s@usach.cl \\ Artículo bajo licencia Creative Commons \\ Atribución 4.0 Internacional (CC BY 4.0) \\ ENVIADO: 2019-05-03 \\ ACEPTADO: 2019-06-11
}

\section{RESUMEN}

El presente escrito trabaja la idea del "cuerpo espasmático" en la historieta “1973 La tormenta” de Ricardo Fuentealba, especie de contrapunto a las historietas modélicas sobre memoria en tiempos de violencia, en que los cuerpos permanecen inalterados. En la historieta de Fuentealba aparece un cuerpo que se ve afectado y afecta los diversos flujos temporales que habitan en el gesto de memoria del protagonista. Específicamente, en el objeto de estudio seleccionado se evidencia, bajo el uso del montaje, cómo el cuerpo capta de manera conflictiva tanto el discurso histórico, que ordena, fiscaliza y determina monológicamente a los cuerpos en un trayecto temporal oficial, como en un tiempo de la memoria que se sostiene en olvidos y en interrupciones del flujo del tiempo oficial.

\section{RESUMO}

Este artigo trabalha a ideia do "corpo espasmatico" no desenho animado “1973 La tormenta” de Ricardo Fuentealba, espécie de contraponto aos exemplares modelos na memória em tempos de violência, em que os corpos permanecem inalterados. Fuentealba mostra um corpo que é afectado e afeta diferentes fluxos temporais que habitam o gesto na memória do ator. Especificamente, o objeto de estudo selecionado é evidente, sob o uso da montagem, como o corpo capta de forma controversa o discurso histórico, que ordena, pesquisa e determina monologicamente aos corpos, num passeio temporário oficial, e um tempo de memória que se realiza em omissões e interrupções no fluxo de tempo oficial.

PALAVRAS-CHAVE

quadrinhos, tempo, memória, corpo, história.

\section{ABSTRACT}

The present work works the idea of the "spasmatic body" in the comic strip “1973 La tormenta” by Ricardo Fuentealba, a kind of counterpoint to the comic models about memory in times of violence, in which the bodies remain unaltered. In the story of Fuentealba appears a body that is affected and affects the various temporal flows that inhabit the gesture of memory of the protagonist. Specifically, in the selected study object it is evidenced, under the use of the assembly, how the body captures in a conflictive way both the historical discourse, which orders, monitors and monologically determines the bodies in an official temporal trajectory, as in a time of the memory that is sustained in forgetfulness and in interruptions of the flow of official time.

KEYWORDS

comics, time, memory, body, history.
PALABRAS CLAVES

cómics, tiempo, memoria, cuerpo, historia 
El presente escrito se posiciona desde una mirada que cruza elementos de semiótica del cómic, representada por autores como Groensteen, Peters y Pintor, y filosóficos, específicamente la idea de inestabilidad que emana de las propuestas bergosianas y deleuzianas. A partir de dicha cocinería teórica pretendo generar un recorrido que evidencie cómo la historieta "1973" de Ricardo Fuentealba presenta una idea de tiempo, memoria y cuerpo que se funda en la inestabilidad. Para aquello definiré un concepto clave como es la viñeta, para luego explicar el contexto de producción de cómic de memoria en que los testigos tienen la potencialidad de no ser afectados por las violencias en contraste con la historieta seleccionada para interpretar. Así la metodología propuesta es articular elementos de forma del cómic y filosóficos con contextos de producción particulares, y cómo en dicha imbricación/tejido surge una lectura particular, en este caso, sobre la memoria, el tiempo y el cuerpo. 


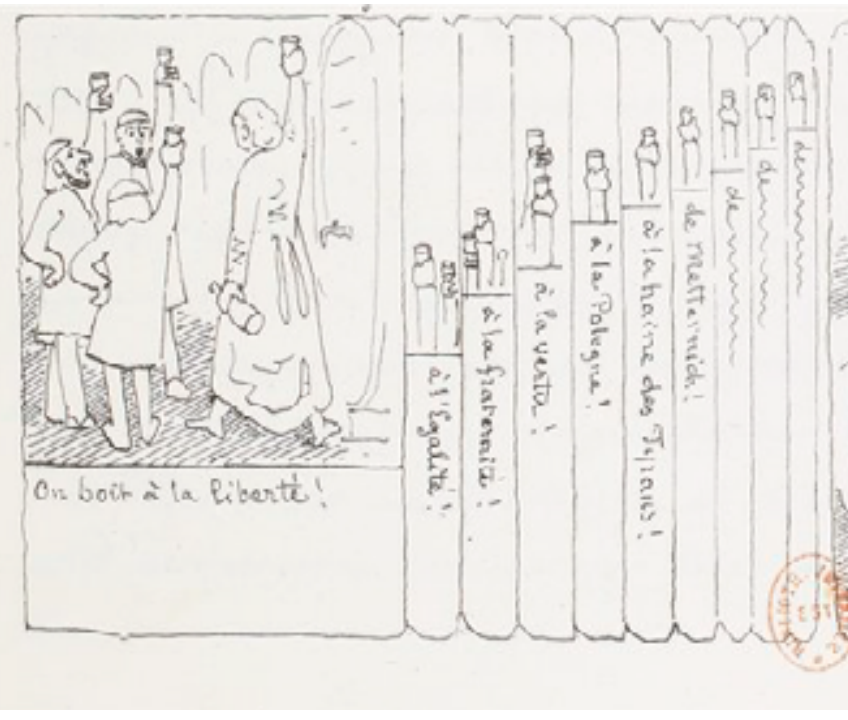

Imagen 1. (Töppffer, 1845: 09)

\section{UNA BREVÍSIMA INTRODUCCIÓN: TIEMPO, MEMORIAS Y CUERPOS EN LA HISTORIETA}

Se puede definir la historieta como un medio que evidencia un hacer del tiempo a partir del empleo del montaje: entre viñetas, dentro de la viñeta, con las nubes, con el texto, con la página, etc. Esto en una tensión entre continuidad y discontinuidad, en una resistencia compleja a la idea clásica de narración y la idea de tiempo que esta sostiene/media ${ }^{1}$, una especie de un avanzar en resistencia y, a la vez, en una caída libre a toda velocidad. El cómic, entonces, entendido como una inestabilidad en la que el lector/lectora no solo completa vacíos de información, sino que generalmente los ve en el gutter, patenta la incompletitud junto con el acto de completar la información.

Ivan Pintor refiere a que Fellini explicaba que "el carácter físico y material de las viñetas se asemeja a las mariposas muertas, cada una de ellas fijada con un alfiler y dispuesta en un orden estricto. Lo que consigue la mirada del lector al recorrerlas es devolverles el aleteo, restituir en ellas el aliento del tiempo" (Pintor 2017). Inestabilidad que Benoit Peters ejemplifica a partir del recurso de la metamorfosis, como un principio que está presente desde los orígenes del cómic, en que los personajes habitan en un "marco mutacional" en el que el cambio de forma, tiempo y estabilidad de los cuerpos es común (1998: 35).

Es dentro de dicha inestabilidad, específicamente la de la viñeta ${ }^{2}$, en la que la pregunta sobre cómo representar y signi-

1 Entiendo la idea clásica de narración a partir de Ricoeur, quien la describe como aquella secuencia teleológica transparente entre sucesos, asociada al discurso histórico que oculta las aporías del tiempo mismo "en virtud de su inserción en la gran cronología del universo" (Galardi, 2011: 114), es decir, soslaya en su misma condición de representación los rasgos no lineales del tiempo. En cambio, en la narración de ficción no existe la intención de enlazarse a un tiempo sin aporías o dar una respuesta globalizadora, en estos relatos se exhiben dichas aporías por el mismo acto de mostrarlas. El filósofo dice que la narración de fic ción no es que omita o se desvincule con el mundo práctico o tiempo vivido, sino que "reorienta la mirada hacia los rasgos de la experiencia que 'inventa', es decir, descubre y crea a la vez" (Ricoeur, 2004(b): 492), exige ir más allá de los rasgos de la experiencia cotidiana, generando una experiencia ficticia del tiempo.

2 Respecto a la inestabilidad, Pintor señala que la mayoría de los teóri cos ven en la viñeta dicha condición, entre los que cita se encuentra Piere Mason que denomina a la viñeta como un "compuesto inestable" (1985) o a Tillevil que enuncia que la viñeta es "una combinación inestable y paradójica entre dibujos y textos" (1991: 31). ficar el tiempo se ha transformado en una constante, aquello se observa ya desde las primeras producciones en la que los autores que inauguran dicho género como Rodolphe Töppffer $(1799$ - 1846), quien emplea un conjunto de estrategias narrativas visuales para representar el tiempo (como la viñeta, la clausura y el montaje), las que usa para tratar temáticas sobre la temporalidad en la modernidad: velocidad del tiempo industrial, fragmentación de la experiencia del tiempo y la relación con la memoria.

Tanto en el clasicismo estadounidense, la edad de oro de la historieta francobelga ${ }^{3} \mathrm{o}$ en las primeras producciones latinoamericanas, se evidencia, en la mayoría de estas, juegos con el tiempo que se adaptan a una norma hegemónica que potencia la noción de continuidad (Pintor, 2017) ancladas al código escrito (como dador determinante de sentido) y la estructura narrativa clásica. Mas luego existe un quiebre, ya desde los años sesenta, en el que se comienza a experimentar, ensanchar los márgenes y dispersar los sentidos posibles que la historieta permite, como enuncia Groensteen:

"The aesthetic evolution of comics for the past quarter of a century has been toward the direction of liberating the image. The traditional narrative drawing, from Töpffer to Franquin, and from Milton Caniff to Meziéres, is seen to be concurrent with writig that is freer, more pictorial, nad more poetic" (2007: 163)

Aquello ha ido provocando una visibilización/espacialización de diversas concepciones sobre el tiempo, abriendo las narraciones a las diversas posibilidades de plasmarla en el texto. Mazur y Danner (2014) sostienen que luego de la Segunda Guerra Mundial "los cómics de todo el mundo respondieron a los cambios demográficos y a la agitación cultural, con lo que sintonizaron con los lectores que maduraban y la aparición de una nueva generación de creadores." (14), siendo la idea de la no continuidad une eje de construcción narrativa o, mejor dicho, el afianzamiento de estrategias que tensionan la idea de una continuidad transparente, motivada y asociada a la forma de la narración histórica, como una de las marcas que nace y se mantiene hasta hoy en día.

3 Tanto el clasicismo estadounidense como la edad de oro de la historieta francobelga son modos históricos de narración del cómic que se posicionan como una primera etapa en el desarrollo del cómic. Ambas se consolidan en los años veinte como formas hegemónicas en el quehacer del cómic en sus respectivas zonas geográficas. 
Al respecto, hay que articular lo anterior con el montaje. Este es una forma común que ha sido empleada para producir efectos de sentido referidos al tiempo. Dicha forma de generar condiciones de representación es parte de un nuevo régimen de imageneidad" que, a decir de Ranciére, toma distancia "frente a cierta forma de medida común, la que expresaba el concepto de historia" (2011: 56). Según Andrés Claro (2016) dicho tipo de figuración es una respuesta al tipo de representación metafórico-analógico, la que subordinaba "una imagen sensible a una ideal” (120) sosteniendo, así, una "metafísica dualista que se diacroniza en una teleología histórica (120). El montaje, en cambio, "tiende a hacer experimentar lo real como una inmanencia abierta al acontecimiento" (130) superando la noción de un referente ideal y del sentido de las partes que vincula.

Claro afirma que el montaje es una figuración propia de nuestra época, operando como una "posibilidad de la representación y la experiencia compartida” (119), así un conjunto de artes como el cine, la arquitectura y la poesía (agrego el cómic) se evidencia la doble operación del montaje y sus efectos interruptivos.

Volviendo puntualmente al cómic, y en particular la viñeta, se puede pensar esta "parte" de la historieta desde su incompletitud, en la necesidad eterna de un montaje siempre posible y deseable con otro elemento estructural presente en el cómic: otra viñeta, textos, imágenes, páginas, etc. Tanto Peeters (1991) como Groensteen (1999) coinciden en aquella necesidad de montaje de la viñeta como condición de representación, la que describen a partir de las nociones de "pericampo" y "solidaridad icónica” respectivamente. En ambos conceptos está la idea de fondo que al observar (leer) una viñeta siempre está el significado de la que presidió o la que viene, al decir de Bordes nunca hay fuera de campo, sino que: "construimos una imagen mental del espacio en el que nos hallamos a través de la suma de vistazos fragmentados" (2017: 35)

Groensteen, tomando en cuenta que dicha condición de representación del tiempo exige una construcción del mismo tiempo, en el que "la composición de la página en su descomposición en fragmentos dotaría de una coordenada temporal" (Bordes, 2017: 35), propone que el marco cumpliría una función rítmica que da continuidad al relato y a la vez lo contiene. Es decir que la viñeta, específicamente su marco, no define una unidad temporal generalizada en el cómic, sino que en el doble gesto de retención y progresión configura, en cada producción particular de la historieta, una representación y experiencia temporal específica y abierta. Esto contrasta con lecturas que vuelcan un tiempo secuencial lógico en los cómics.

En este sentido y como ya se mencionó, desde los años sesenta existe un corpus determinado de cómics en el que se produce una transgresión del lenguaje, develando como en la experiencia del tiempo la discordancia habita y en la narración de la historieta se puede leer una dimensión configurante que no soslaya dicha experiencia, es más, se potencia, empleando el montaje para intencionar efectos de significación interruptiva. Así, "construir una historieta no es ilustrar una historia sino, ante todo, gestar diagramas narrativos que contengan tiempo" (Pintor, 2017: 20).

El concepto "régimen de imageneidad" lo empleamos a partir de Jacques Ranciére (2011), quien lo define como una forma de ser la imagen en un contexto determinado.
Dentro de este corpus destaca el tema de la memoria. Ya desde los años ochenta existen, cada vez más, historietas que desean dar testimonio de un hecho. Problemas familiares, hechos de violencia y relecturas de periodos particulares, entre otros, son temas/problemas sobre los cuales este género se ha focalizado.

Un ejemplo que influye hasta hoy en día es "Maus" (1980) de Art Spiegelman, el cual emplea las particularidades formales de la historieta para tensar las nociones históricas tradicionales sobre el Holocausto. Dominick LaCapra (2009) sostiene respecto a esta historieta que la hibridación entre las imágenes y el texto producen efectos en el receptor que, al parecer, son más efectivos que los expresados solo por lo escrito: "Acaso la conjunción de imagen y palabra ofrece un medio más efectivo de transmisión que la palabra por sí sola?" (p.198) se pregunta LaCapra, generando la hipótesis que las condiciones estructurales de esta historieta exigirían procesos de recepción distintos a los de otras producciones que, lejos de apostar por una transparentabilidad del mensaje, tensarían a los discursos y estructuras tradicionales de memoria.

Hilary Chute, en este punto, destaca como desde "Maus" las historietas se han preocupado no solo por narrar historias de superhéroes, sino que se han centrado en el problema de la representación de la memoria y la violencia, enfrentando las tradicionales formas de narrar el pasado (2008: 458). La teórica de comics estadounidense ha destacado la importancia de autores como Satrapi, Sacco, Nakasawa y el mismo Spiegelman como producciones que a partir de su particular disposición testimonian un pasado: "Throgh its spatial syntax, comics offer opportunities to place pressure on traditional notions of chronology, linearity and causality" (2016: 4).

La historieta, así se ha configurado como una forma de hacer/ recoger memoria posicionándose, en la mayoría de sus producciones, marginal frente a los relatos históricos. Marginal en un doble sentido, uno respecto a la idea teleológica que domina el discurso histórico, y otra como un tipo de texto infantilizado y reducido solo a contar historias de superhéroes. En este escrito me detendré en la primera marginalidad.

Traverso (2012) explica la diferencia entre historia y memoria. La primera la define como: "una reconstrucción de los hechos y los acontecimientos del pasado tendientes a su examen conceptual y a su interpretación" (282), subrayando que es un espacio de pensamiento que ha monopolizado y clausurado las lecturas sobre el pasado a partir de una lógica teleológica. La memoria, por su parte, la define como: "una representación del pasado que se construye en el presente, es el resultado de un proceso en el que interactúan varios elementos" (285) compuesta por recursos individuales y representaciones colectivas del pasado.

La tensión entre historia y memoria que surge de la propuesta de Traverso se puede pensar como la tensión entre una narración, la histórica, que desea imponer la lógica de la causalidad en la que la que no hay contradicciones ni ambigüedades, como sentencia Cuartango: “...el aplanamiento del tiempo, su conversión en una serie de instantes iguales unos a otros, puede ser visto como una consecuencia de la primacía de la razón para la que todo es calculable, utilizable y descualificado" (2007: 202). Por otro lado, está la memoria, como una narración que puede asumir su fragmentariedad y posibles contradicciones.

En esta tensión un punto clave es la clausura que propone la 
historia, la que encapsula una serie de hechos en una secuencia extrayéndolos del presente, un quiebre/abismo que la memoria lo asume desde la coexistencia de un pasado (transformado, mediado, fragmentario) y el presente, abriéndose a posibles narraciones otras que la historia no consideraba o las pensaba como irrepresentables, apelando al presente, como enuncia lleana Diéguez: "La memoria adviene en imágenes dispersas, como un resplandory algo arde y molesta en esas imágenes que nos confrontan con nuestro propio malestar" (2017: 17).

Ante esta delimitación comparativa entre historia y memoria existe un corpus de historietas que se posiciona como un ejercicio de memoria. Para explicar esto me interesa justificar el nombre con el cual he escogido nominar el texto interpretado: historieta. Es sabido que la nominación es una particularidad en este tipo de textos, ya que, dependiendo de la zona cultural se le denomina de diversas maneras: cómic en Estados Unidos, tebeo en España, fumetti en Italia, bande dessinée en Francia y Bélgica, Manga en Japón, Pepines en México e Historieta en gran parte de Latinoamérica (en Brasil es quadrinhos o Gibis).

En el caso latinoamericano es interesante la apelación paródica a la narración histórica, en tanto se propone como una narración otra a la Historia, ahora se es historieta, asumiéndose como un discurso mínimo, poco serio, en el que, si bien recoge aspectos claves como la secuencialidad causal en la gran mayoría de los casos, se quiere asumir como ajena a las grandes discursividades.

Cabe mencionar que las primeras historietas, por lo menos en EEUU y Chile, aparecían en los diarios, otra gran tecnología de la narración y del archivo de la memoria oficial, pero la historieta era una especie de apéndice, de irrupción extraña y alterna a las noticias o reportajes. Historieta, no historia entonces, en el sentido de tener el espacio para no regirse por lo oficial, ni en forma ni en contenido.

El cuerpo en las historietas más reconocidas que trabajan el tema de la memoria en contextos de violencia (Por ejemplo: "Maus" de Spiegelman; "Persépolis" de Satrapi; "El último asalto" de Tardi, "Palestina" de Sacco) se han caracterizado por una representación que se rige por la adecuación a una lógica cronológica y estable. Es decir, se mantiene igual en todo el texto, afectándose solo por el paso del tiempo concebido como duración (secuencia lineal pretendidamente objetiva y medible). Una excepción podría ser "Maus" pero, aun cuando juega con la animalización de sus personajes, marca límites claros, el cambio entre cuerpo humano y el de ratón es alegórico y permanente, además, en cada espacio de realidad (el de humanos y el de ratones) existen mutaciones enlazadas con la lógica temporal histórica.

Dicha estabilidad se tensa con la idea de metamorfosis que describí al inicio de este escrito, y que refiere a la inestabilidad de las imágenes y estructuras en general de la historieta (Peeters, 1998: 35). Aquello, en general, no se evidencia en las historietas que abordan temas de memoria, en dichos casos, los cuerpos se adecuan a una normativa representacional preestablecida.

Esto produce extrañeza, ya que en producciones que desean desafiar a la narración histórica tradicional, se cae en representar el cuerpo tal cual discurso histórico conservador: eterno, relacionado solo con las grandes discursividades, alejado de las sensaciones y sentires frente a los hechos. Aquello se refleja en Hilary Chute quien en su estudio sobre historieta testimonial agrupa tres textos que asume como representativos del canon: "I saw it" de Keiji Nakasawa, "Maus" de Art Spiegelman, y "Palestina" de Joe Sacco, tres historietas que pretenden, según la autora, ser una mirada testimonial de hechos de violencia que "Driven by the urgencies of re- seeing the war in acts of witness, comics proposes an ethics of looking and reading intent on defamiliarizing standard or received images of history while yet aiming to communicate and circulate" (2016: 31), sin embargo sostengo que dicha desfamiliarización no atañe al cuerpo, este se posiciona como una materialidad privilegiada que no sufre las violencias, protegida por la lógica temporal de la duración histórica. Lo mismo sucede en el texto "Comics and memory in Latin America” (Catalá, Drinot y Scorer, 2017) que selecciona textos latinoamericanos que trabajan el tema de la memoria en contextos de violencia en Latinoamérica, los que nuevamente funcionan como una narrativa que "muestra" hechos soslayados por lo oficial, con cuerpos testigos/protagonistas que se adecuan a una racionalidad temporal cronológica. Entonces, en estos dos estudios críticos, que se pretende agrupar textos modélicos referidos a la memoria, los cuerpos son representados dentro de la idea de la estabilidad, ven sin ser afectados, observan de forma omnisciente, clara y distinta.

Así, existe una concepción de tiempo, de mostrarlo, que afecta las narraciones de memoria, monopolizando la idea de un cuerpo protagonista y testigo privilegiado, que puede observar los hechos sin ser afectado. No obstante lo anterior, existen historietas en que se problematiza la representación de la afección del cuerpo por el tiempo, superando la idea de una construcción corporal basada en una materialidad idéntica, transparente y anclada a la lógica de la duración histórica. Un ejemplo es “1971 La Tormenta” realizado por Ricardo Fuentealba. En este, surge la representación de un cuerpo espasmódico, en el que no se superpone narración histórica y memoria, sino que las muestra atravesando, a la vez y mezcladas, el cuerpo del protagonista. 


\section{CUERPOS ESPASMÁTICOS}

"Los cuerpos son relaciones antes que cosas" (Bulo, 2018: 79)

Ricardo Fuentealba es dibujante y guionista que participó en los años ochenta en revistas de culto como Trauko y Ariete. Uno de sus clásicos personajes es el Conde de Matucana, creado en plena dictadura en la revista Matucana, "especie de Vampiro ávido de sexo, tiernos cuellos y turgencias varias" (Reyes, 2006: 220). El hábitat artístico/comiquero de dichos años se caracteriza por el boom de las revistas independientes, las que se posicionan como una resistencia a la violencia dictatorial y que estaban influenciadas por artistas como Moebius, Crumb y la revista argentina Fierro (216).

Su última producción es la historieta "1973", publicada en el 2018, recoge tres narraciones gráficas: "El Yanacona”; “1973. La Tormenta" y "El muchacho héroe del puente Pío Nono". En estas se hace un relato visual de memoria sobre la dictadura, su violencia y su actualidad. Lo interesante es que es son escritas desde un ahora, por un autor que tuvo la experiencia de sufrir aquellos sucesos. Acá hay un gesto de memoria de un testigo/autor, a diferencias de otras producciones escritas por los "hijos de la dictadura" como "Los años de Allende" (Reyes y Elgueta, 2017) o “El Golpe: El pueblo 1970 - 1973” (Cruz, 2014).
El análisis que realizaré, como ya enuncié, se centra en una de las historietas incorporadas: “1973. La Tormenta". En esta los cuerpos que aparecen: sin rostro, desfigurados, borroneados, salidos de la viñeta, entre viñetas o incompletos y/o que (des)aparecen, llevan a pensar el cuerpo más que como un órgano que se adecua a la estructura temporal histórica con la capacidad para "ver" (entendiendo ver como captar un "buen cuerpo", su masa, forma y medida) a entenderlo como un estar(se) siendo a partir de una inestabilidad constante.

Dado el contexto anterior, la hipótesis que deseo argumentar es que en la historieta "1973. La Tormenta" de Ricardo Fuentealba se presenta una idea de tiempo que afecta a los cuerpos, los que escapan a la lógica figurativa que está presente en gran parte de las producciones modélicas sobre narraciones de memoria en los cómics. Aquello se produce, como ya se mencionó, a partir de la transgresión de la estructura tradicional del tiempo: transparente y secuencial, siendo afectado el cuerpo, recibiendo/expeliendo diversos flujos temporales que influyen en el gesto de memoria.

Lo dicho se articula con la idea de flujos del tiempo desarrollada por Henry Bergson. El filósofo parte de la noción que la realidad es un movimiento continuo "El movimiento es la realidad misma" (1911: 1) sentencia, en donde la duración (el tiempo) es indivisible, heterogénea e implica la conciencia. Esta involucra diversos flujos que no necesariamente son perceptibles, pero que acaecen en el sujeto a cada momento. Un aspecto clave es que la duración siempre es personal, no existe un tiempo impersonal, así cada sujeto vive en el tiempo, tiene una conciencia particular.

Ante aquello la noción de tacto y afección son conceptos que juegan un rol clave en las condiciones de representación de los cuerpos. En dicha tensión: mirar - tocar, se supera la idea del mirar, del ser un testigo, como una acción captadora desconectada del tacto y los otros sentidos. Así, a partir del mirar y los sentidos entendidos como una amodalidad perceptiva, es decir, que los sentidos funcionan de manera conjunta y su división es ilusoria, es que existe una coimplicación de todos estos. Configurándose un estrato en el que los sentidos se continúan unos a otros más que una conjunción posteriori.

El tocar, partir de lo anterior, lo entiendo desde lo háptico lo que "incluye el tacto, entendido en sentido literal y metafórico, y no puede sino pensarse junto a él” (Maurette, 2015: 54), una forma de visión táctil, que "hace de la narración algo tangible" (74), lo que plantea una simultaneidad entre el afectar y ser afectado.

La memoria, entonces, aparece en la historieta como un acto de afección de diversos flujos temporales que actúan sobre el cuerpo de manera conjunta. El cuerpo no es una materialidad ajena al tiempo, como en la mayoría de las producciones sobre memoria, en el que su posición privilegiada de testigo lo exime de los sentires del tiempo. Por otro lado, el cuerpo se asume también como un irradiador de flujos temporales, recibe y da, a la vez. 

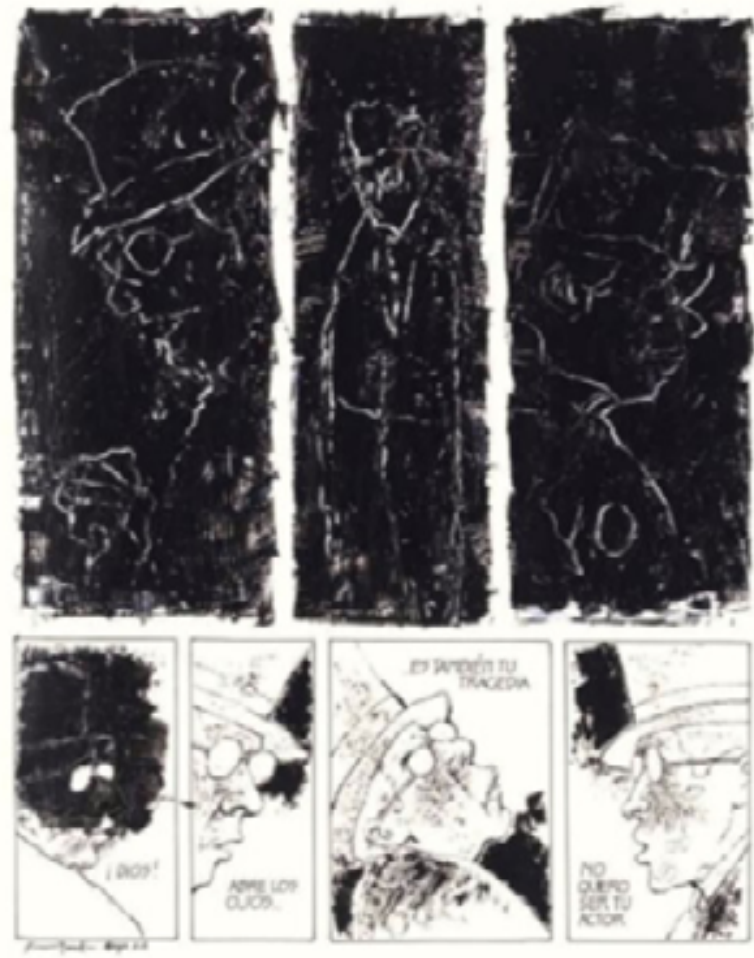
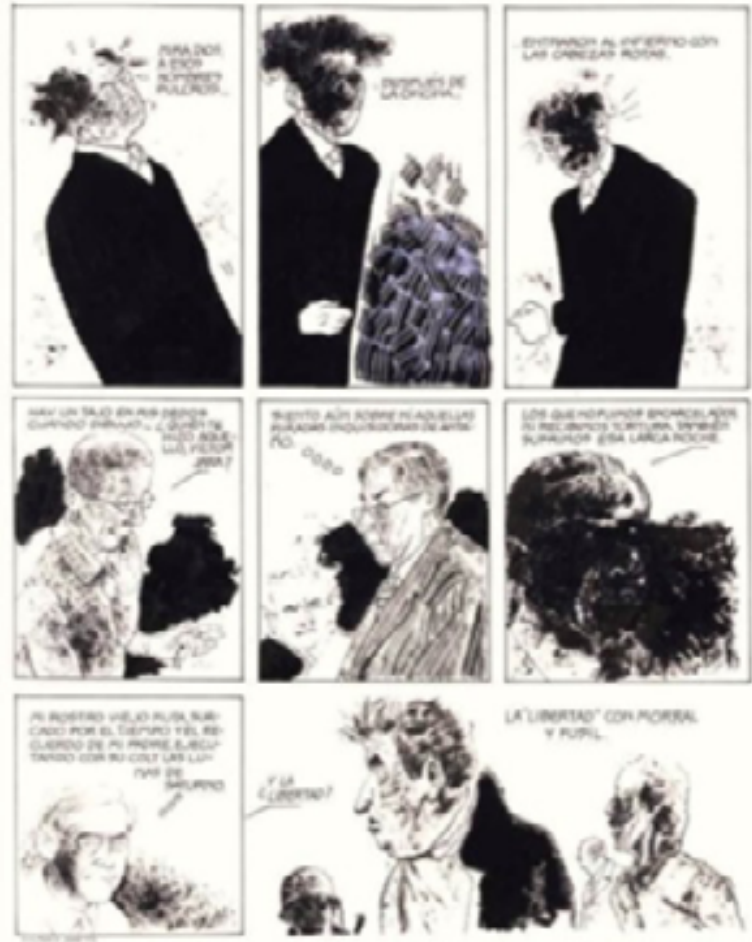

Imagen 2. (Fuentealba, 2018: 46 - 47)

En las dos planchas anteriores se ven las mutaciones corporales del protagonista, quien se encuentra recordando el golpe de Estado chileno de 1973. En las viñetas el cuerpo no se mantiene igual, en la primera plancha se observa solo su silueta, su rostro borroneado y su cuerpo más definido bajo las lógicas tradicionales de la representación del cuerpo. En las primeras tres viñetas de esta plancha se puede leer/ver desde una lógica no basada en la secuencialidad, ni con una base histórica transparente, pero no por eso bajo un "irrepresentable", ya que acá hay un cuerpo en su espasmo, que trata de generar un límite con el fondo negro, de lograr ser una figuración ${ }^{5}$ clara de un cuerpo, pero que claramente no lo logra, como se ve en la segunda viñeta, que no calza para nada con los límites corporales de la primera y tercera viñeta, llegando a instalar en la tercera un "YO" dentro de su cuerpo, pero un cuerpo que está cargado del afuera negro, un dentro/afuera que está en todo. Así el límite quebrado, frágil, movilizado, resulta que no puede fijarse, sino que se un movimiento sin direccionalidad constante, es puro flujo.

Se puede pensar esas líneas como la piel, para esto el concepto "figura" de Deleuze resulta adecuado, quien plantea, a partir de su interpretación de cuadros de Bacon, que en dichas obras del pintor soslaya las representaciones figurativas y abstractas, ambas ligadas a lo narrativo y al intelecto respectivamente, para llegar a la figura. Esta se caracteriza por representar al cuerpo, por así decirlo, “cuerpeándose”, siendo, escapándose a discursos configuradores, estructurados y definitivos, rompiendo con la dicotomía objeto - sujeto. La piel en ese sentido no como un límite de interioridad y exterioridad predefinida, sino que una suerte de membrana espesa producida por un

5 Entiendo “figuración” desde Deleuze, quien la significa como la prác tica artística (particularmente la pintura) que intenta captar la forma de un objeto exterior, en oposición a lo abstracto. constituyente de las cosas que permanentemente se van exteriorizándose y adentrándose.

Así, en esta historieta el cuerpo tiene espasmos, dentro de lógicas y secuencias aparentemente contradictorias: negando el discurso histórico, adecuándose a él, para luego otra vez negarlo. Como en la última viñeta de la primera plancha en que el personaje se dirige al autor diciendo: "no quiero ser tu actor", la que se tensa cuando en la plancha que sigue, que con un dibujo mucho más figurativo se enuncia: "Mi rostro viejo muta, surcado por el tiempo y el recuerdo de mi padre, ejecutando con su colt las lumas de Saturno", para luego, en otra viñeta, nuevamente explotar en figura.

Los cuerpos, sus cabezas, estallan, se ensombrecen, pero también captan la narración histórica, así no excluyen flujos, sino que se ven afectados por esta y a la vez afectan la narración, hay muchos cuerpos dentro de un mismo cuerpo queriendo escapar y/o quedarse, o mejor dicho vibrar dentro de una misma materialidad.

La historieta presenta cuerpos incompletos, en espasmos, que están en el olvido, "cuerpeándose" en/desde la memoria asumiendo el espasmo del olvido, pero que a la vez, está afectado por el discurso más conservador de la historia y del cuerpo, ni monstruo ni figuración, sino que un espasmo. En este sentido se puede vincular con el recurso estilístico de la metamorfosis ya descrito, ya que se asume en /dentro de la inestabilidad.

Un ejemplo es el que se da en la segunda plancha de la historieta, en la que se presentan dos cuerpos, bajo un recurso narrativo que Groensteen denomina incrustación, a decir, cuando una imagen (viñeta) es el fondo de otra viñeta, generando una temporalidad paralela (Bordes, 2017, p.46). A diferencia de las transiciones comunes entre viñetas acá, siguiendo la lectura de Groensteen, sucedería un “en mientras” más que un "y enton- 
ces". En uno, ubicado en la parte superior derecha se muestra su rostro en primer plano enunciando: "mi relato". El segundo ocupa gran parte de la página y tiene un texto que dice: "Con un lápiz y sombrero de copa en el teatro inmensa tragedia". El texto, presenta borrones. Dos flujos temporales que conviven, dos cuerpos vinculados por el marco de la viñeta, uno es una figuración, anclado con la idea del relato, un cuerpo que observa la historia y es afectado por esta, es más, es un cuerpo que observa (afecta, toca) al lector(a); el otro un cuerpo en espasmo, no es la irrepresentabilidad, sino que la figura del espasmo del cuerpo afectado y afectando la memoria de la violencia.

Lazzara respecto a este comic enuncia que el cuerpo representado está trizado y es afectado por el gesto de memoria “...el artista se autorretrata en varios momentos. Pero su subjetividad es móvil y fragmentada, igual que sus recuerdos. Lo vemos joven y viejo. Asistimos a sus diversos estados psicológicos: la pesadilla, la nostalgia, incluso la locura" (2018: 11). Así, se supera la dicotomía entre ver/no ver, cuerpo/monstruo, ver/tocar, por un cuerpo que devela la trizadura, la incompletitud y movimiento de la memoria, como un cuerpo que desborda y que está en una permanente constitución y descontitución en el acto del recordar los hechos de violencia de forma subjetiva. El segundo cuerpo que aparece en las viñetas anteriores, no es el que cumple con el monopolio de un solo sentido, sino lo devela dentro/fuera de la afección, como una acción que no es ni previa ni posterior, sino como un movimiento permanente que siempre está, tal como sentencia Nancy al referirse al tacto: “Todo mi ser es contacto. Todo mi ser es tocado/tocante" (16).

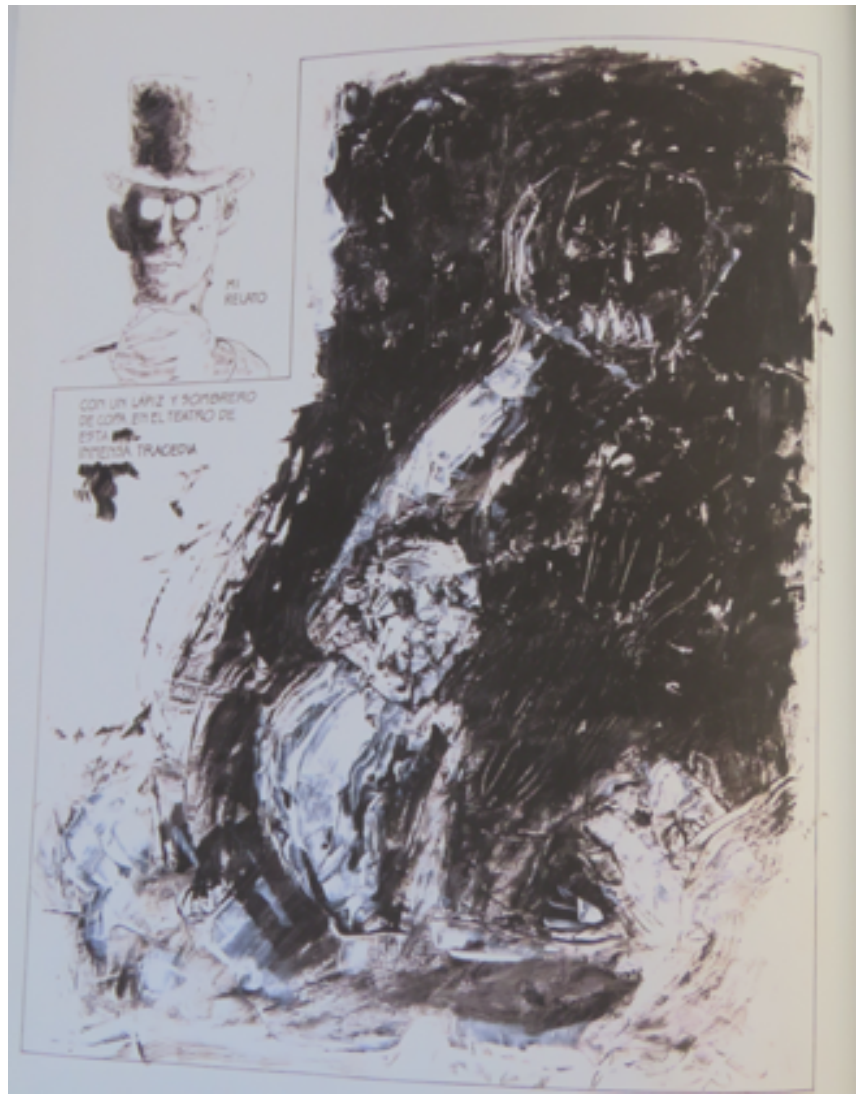

Imagen 3. (Fuentealba, 2018: 40)

En las 8 páginas finales representan un enlodamiento de la diégesis de la narración en que el cuerpo espasmático se desmonta definitivamente del cuerpo referencial, tesigo/autoral. En dichas páginas se produce un enlodamiento y no quiebre, una nueva espacialización del mismo flujo temporal en la lógica de la inestabilidad propia de las historietas. Dichas páginas están precedidas de una plancha que lleva escrito lo siguiente:

Así eran esos días, un grito. Un sonido metálico. Una voz de mando, era señal de alarma, de cerrar ventanas... O un reflector dibujando el miedo en los muros de las casas. El seco Crap Crap de un Sig, el Rat ta ta lejano de una punto 20, podría ser la muerte caminando (53)

Última voz del protagonista/autor/testigo. Luego vienen macroviñetas de diversos cuerpos, que expresan una desaceleración brusca de las viñetas anteriores, en que se solapan, textos e imágenes que quieren ser recortes de otros flujos pasados acoplados a un flujo del presente. Citas a poemas, referencias a "héroes nacionales" confluyen con fragmentos de memoria "Lo vi en la plaza de armas de mi pueblo natal" (54) o figuras rehechas por medio del montaje produciendo un efecto de sig nificación interruptiva montando dos o más elementos/textos/ imágenes a partir de la fragmentación perspectivista y yuxtaposición reveladora, operación básica de este tipo de estrategia de generación de sentido (Claro, 2016: 118).

La producción de un efecto temporal está basada tanto en este enlodamiento del tiempo como en estos cuerpos atrapados/mezclados en el espacio. Acá desaparece el cuerpo narrador/testigo y surgen cuerpos espasmáticos, en general, sin fondos, sin otro espacio que el sentir sobre la memoria violenta, o si hay un fondo, los cuerpos se dibujan plegados a dicha espacialidad.

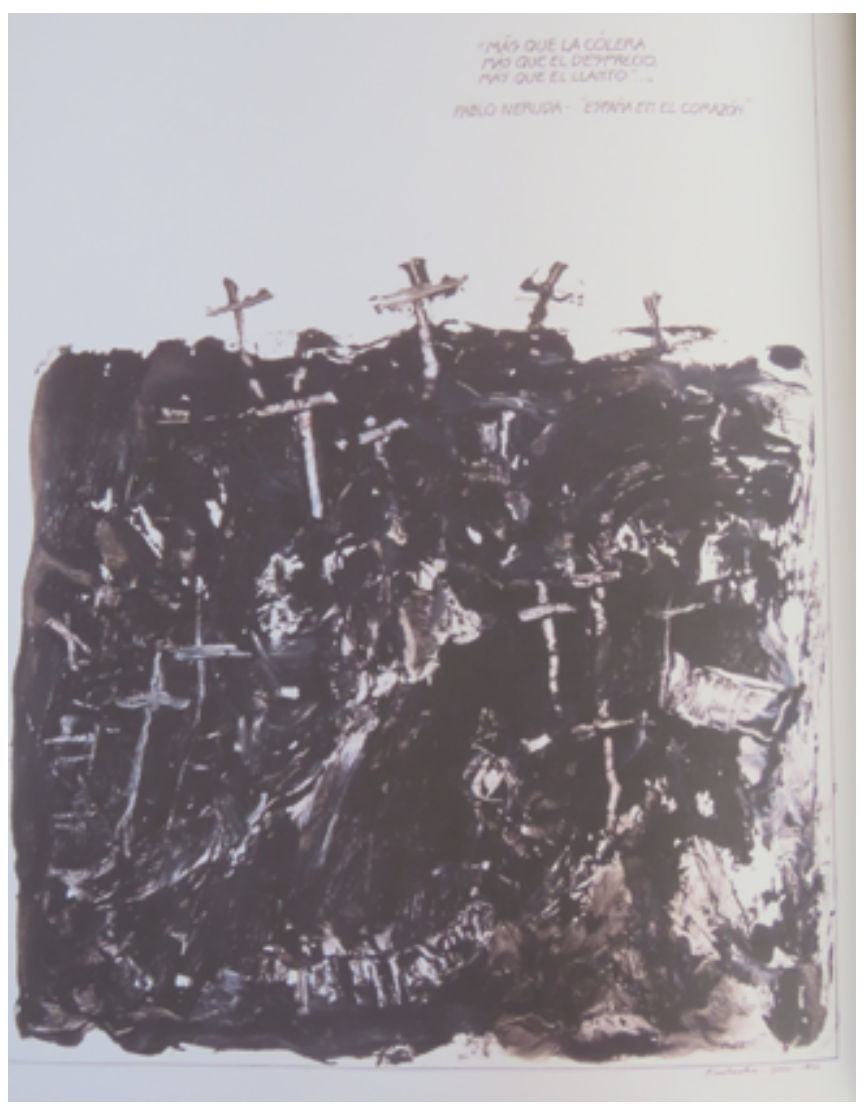

Imagen 4. (Fuentealba, 2018: 60) 
Para finalizar, se puede concluir que la historieta analizada soslaya las concepciones tradicionales del testigo. Este, en general, se dispone como un cuerpo no afectado por las violencias que observa o relata. Acá, en cambio, mediante la particular disposición y uso de las viñetas se presenta un colapso sintáctico de lo oficial, llevando a la memoria y los cuerpos a la inestabilidad. Así, este reconfigurar el tiempo y colocar en escena al cuerpo en espasmos es a fin de cuentas un reclamo por un régimen visual de la memoria que se declara unívoco. Lazzara refiere sobre el cómic que la apuesta visual “... se vuelve una estrategia para rescatar del pasado a un ser anónimo -un ser político- con la intención de restaurarle una existencia y rendirle homenaje a contracorriente de las inercias olvidadizas de nuestra actualidad" (10). Es el uso particular del montaje que refigura la concepción de tiempo en pos de la representación de cuerpos fusionados con fragmentos de duración, complicándose mutuamente, en donde el "propio acto de dibujar se convierte en una herida abierta” (Zúñiga, 2018: 13), reclamando un no a la historia y un sí a la historieta. 
Bordes, E. (2017). Cómic, arquitectura narrativa. Madrid: Cátedra.

Bulo, V. (2018). El frote de las diferencias o el placer de las cosas. En Acontecimientos corporales. Desplazamiento en las prácticas artísticas. Árevalo, Sofía; Motto, Carla \& Sánchez, Jorge editores. Pólvora: Santiago, pp: $79-89$.

Chute, H. (2006). The shadow of a past time: history and graphic representation in Maus. En Twentieth Century Literature. Verano 2006, 52, 2. Pp 199 - 231

Chute, H. (2016). Disaster Drawn. Visual witness, historieta, and documentary form. London: The belknap press.

Deleuze, G. (1984). Francis Bacon. La lógica de la sensación. traducción de Ernesto Hernández, Revista "Sé cauto", Edición digital.

Guerra, C. Acerca de los conceptos de trama y ritmo: una aproximación desde Paul Ricoeury otros autores.

Foucault, M. (2000). Los Anormales. México: Fondo de Cultura Económica.

Fuentealba, R. (2018). 1973 La Tormenta. Santiago: Pehuén.

Galardi, P. (2011). La reconfiguración del tiempo en la narración historiográfica según Paul Ricoeur. En Estudios de Historia moderna y contemporánea de México. N. 41, enero-junio. Pp. 103-115.

Groensteen, T. (2007). The system of comics. Mississippi: University Press of Mississippi.

Lazzara, M. (2018). Retazos de la memoria. En Fuentealba 1973 Santiago: Pehuén.

Maurette, P. (2015). El sentido olvidado. Ensayos sobre el tacto. Buenos Aires: Mardulce editorial.

Mazur, D. \& Danner, A. (2017). Cómics una historia global, desde 1968 hasta hoy. Blume: Barcelona.

Nancy, J. (2013). Archivida. Del sintiente y del sentido. Buenos Aires: Quadrata.

Peeters, B. (1998). Lire la bande dessinée. París: Flammarion.

Pintor, I. (2017). Figuras del Cómic. Forma, tiempo y narración secuencial. Aldea Global: Barcelona.

Reyes, C. (2007). Breve e incompleta mirada a la antigua - nueva historieta independiente chilena. En Revista de Teoría del Arte. N 14 pp. 215 - 233.

Töppffer, Rodolphe. (2003). Essai de physiognomonie. Bibliothèque nationale de France.

Zúñiga, R. La mano alzada, la voz del dibujo. En Fuentealba 1973 Santiago: Pehuén. 
